\title{
ASSOCIATIONS OF NUTRITION AND BODY COMPOSITION WITH CARDIOVASCULAR DISEASE RISK FACTORS IN SOLDIERS DURING A 6-MONTH DEPLOYMENT
}

\section{TARJA NYKÄNEN ${ }^{1}$, KAI PIHLAINEN² ${ }^{2}$ HEIKKI KYRÖLÄINEN ${ }^{3,4}$, and MIKAEL FOGELHOLM ${ }^{5}$}

${ }^{1}$ Finnish Defence Forces, Lappeenranta, Finland

Army Academy

${ }^{2}$ Finnish Defence Forces, Helsinki, Finland

Training Division of Defence Command

${ }^{3}$ University of Jyväskylä, Jyväskylä, Finland

Faculty of Sport and Health Sciences

${ }^{4}$ National Defence University, Helsinki, Finland

Department of Leadership and Military Pedagogy

${ }^{5}$ University of Helsinki, Helsinki, Finland

Department of Food and Nutrition

\begin{abstract}
Objectives: This observational follow-up study investigated the associations of nutrition and body composition with cardiovascular disease (CVD) risk factors, including pro-inflammatory biomarkers, in soldiers during a 6-month deployment. Material and Methods: Thirty-five male soldiers were assessed at months 0,3 and 6 , and their parameters, i.e., $\mathrm{M} \pm \mathrm{SD}$, were as follows: age $30.0 \pm 8.7$ years, height $179 \pm 6 \mathrm{~cm}$, and $\mathrm{BMI} 24.2 \pm 2.5 \mathrm{~kg} / \mathrm{m}^{2}$. Three-day food diaries were used for monitoring macronutrient intake. Body composition was estimated using bioimpedance. Fasting blood samples for lipids and pro-inflammatory biomarkers were collected, and blood pressure measurements were performed. Results: Carbohydrate intake increased and protein intake decreased at month $3(p=0.034, p<0.001)$, while body composition remained stable. Systolic blood pressure increased at month 6, while other CVD risk factors remained within the reference values. Fat mass and body fat percentage were associated positively with total and low density lipoprotein (LDL) cholesterol concentrations at all measurement points. A negative association was found between the change in fiber intake vs. the change in total $(r=-0.36, p=0.033)$ and LDL cholesterol $(R=-0.39, p=0.019)$. Conclusions: Lower fiber intake and a greater amount of body fat were associated with high total and LDL cholesterol concentrations. Nevertheless, the measured CVD risk factors remained within the reference values, except for the higher systolic blood pressure. A regular screening of body composition and a higher consumption of fiberrich foods may promote cardiometabolic health in soldiers. Int J Occup Med Environ Health. 2020;33(4):457-66
\end{abstract}

Key words:

blood pressure, cholesterol, soldier, body fat, fiber intake, crisis management

Received: September 14, 2019. Accepted: March 3, 2020.

Corresponding author: Tarja Nykänen, Finnish Defence Forces, Army Academy, Lavolankatu 1, 53600 Lappeenranta, Finland (e-mail: tarja.nykanen@mil.fi). 


\section{INTRODUCTION}

Cardiovascular diseases (CVDs) are primary causes of mortality in western countries [1]. The CVD risk factors include behavioral (smoking, diet, physical activity, alcohol consumption), physiological (blood cholesterol, hypertension, blood glucose, BMI), and metabolic disorders [1].

Soldiers are typically young and physically active but their CVD risk can be increased as well, especially when they are overweight or obese [2,3]. Compared to civilian populations, soldiers generally have a low incidence of CVD risk factors, which can be explained by regular exercise, high aerobic fitness and/or heredity. However, the globally increasing overweight and obesity trends cannot be avoided in military populations. For example, $44.2 \%$ of individuals, upon commencing their service in the U.S. Army, have been reported to be overweight or obese [3]. Overweight and obese soldiers are at a higher risk of elevated levels of serum lipids and other CVD risk factors $[3,4]$. A low socio-economic position and an inadequate nutrient intake are also associated with an elevated CVD risk $[5,6]$. On the other hand, military work can improve cardiometabolic health by lowering the levels of lipids and blood glucose, provided that diet and exercise are wellbalanced during military training [6,7].

The associations of dietary fat intake and CVD risk factors have been widely investigated and the results are quite clear: a shift from saturated fatty acids (SFAs) towards unsaturated fatty acids is beneficial for human health [8]. Thus, dietary guidelines have summarized that a restriction of SFAs, and an increase in mono- and polyunsaturated fatty acids (MUFAs, PUFAs), may promote cardiometabolic health [9].

The limitation of refined carbohydrates with a high glycemic load is also highly recommended to prevent CVDs [10]. The quality of carbohydrate sources may be as important in preventing dyslipidemia as the quality of fats [10]. An increased protein intake from plant sources might re- duce blood pressure [11], and a replacement of refined carbohydrates with protein may reduce the low density lipoprotein (LDL) cholesterol and triglyceride (TG) levels [12].

It was found that U.S. soldiers, when staying in a military base, consumed fewer carbohydrates and more fat than recommended [13]. In addition, U.S. soldiers, consuming $>3$ servings of beverages or other sugar-containing juices, had a greater risk of elevated TG levels than those who did not [3]. In Brazilian cadets, high intakes of saturated and unsaturated fatty acids were observed [5]. The study performed during a military operation revealed that soldiers consumed $43-46 \%$ of their total energy (E\%) from carbohydrates, 34-35 E\% from fats, and 16-17 E\% from protein [14], i.e., their dietary patterns were close to the general population. Overall, soldiers might have a higher risk for cardiometabolic disorders, both while staying in a base and during operations, if their diet includes low amounts of fiber-rich carbohydrates and high amounts of SFAs. Negative changes in body composition have also been shown to predict CVDs in U.S. Army soldiers [2]. Diagnosed overweight or obesity may subsequently lead to hypertension or the prevalence of other CVD risk factors. While BMI is commonly used as a measure of overweight or obesity, its role is unclear as a predictor of CVDs [15]. Compared to BMI, percent body fat $(\mathrm{BF} \%)$ or waist circumference are more accurate measures of fat mass and fat distribution, thus they may be more suitable predictors of cardiometabolic disorders [16]. Soldiers in military tasks and operations might replace their fat free mass with fat $[14,17,18]$, which may subsequently lead to metabolic problems.

Inflammation is associated with most of the cardiovascular events in the development of CVDs [19]. Pro-inflammatory biomarkers, such as tumor necrosis factor- $\alpha$ (TNF- $\alpha$ ), interleukin-6 (IL-6) and C-reactive protein (CRP), have been shown to associate with CVD risk factors [19]. In soldiers, war zone experiences and combat stress can cause 
low-grade chronic inflammation [20], which may also promote vascular events together with other risk factors. Military personnel may serve several months or years in deployments, being exposed to stressful environments. Thus, physiological, nutritional, and behavioral aspects need to be considered to minimize cardiometabolic disorders. The aim of this study was to investigate the associations of dietary intake and body composition with CVD risk factors and pro-inflammatory biomarkers during a 6-month deployment for a crisis management operation.

\section{MATERIAL AND METHODS}

Thirty-five male crisis management soldiers volunteered for this study during the preparation period, and their parameters, i.e., mean \pm standard deviation (SD), were as follows: age $30.0 \pm 8.7$ years, height $179 \pm 6 \mathrm{~cm}$, BMI $24.2 \pm 2.5 \mathrm{~kg} / \mathrm{m}^{2}$. The study was planned and carried out according to the guidelines of the Ethical Committee of the Central Finland Health Care District. Measurements were conducted 3 times (at months 0,3 and 6) during a 6-month operation in Southern Lebanon. Baseline measurements were performed after an acclimatization period lasting min. 2 weeks.

The main purpose of the crisis management operation was to monitor the cessation of hostilities and support the Lebanese government, armed forces as well as local population. Typical soldiers' duties included patrolling the operational area for 4-6 h, mainly by vehicles, and guarding the military base. The duties were performed in 3 shifts, around the clock. The security situation was relatively calm, although tension in the operational area increased in the midphase of the deployment. The military base was situated on a hill (775 $\mathrm{m}$ above sea level), the mean temperature of the military camp was $22.3 \pm 4.3^{\circ} \mathrm{C}$ (a range of $11-36^{\circ} \mathrm{C}$ ) and the mean humidity was $54.0 \pm 17.2 \%$ (Thermochron, iButton, Maxim Integrated, San Jose, California, USA).

Food diaries were collected for the calculation of nutrient intake at months 0,3 and 6 during the operation. The par- ticipants recorded all the food, fluid, and supplements consumed for 3 days using household measures and standard units. The soldiers were advised to record their intake immediately after each meal and to keep their diet as normal as possible. Items consumed daily, such as bread, drinks and spreads, were weighed and recorded by the research group. Breakfast, lunch, and dinner were served daily in the canteen of the military base, except on Sundays when only brunch and dinner were served. The participants were able to buy some meals and snacks in restaurants and shops outside the camp. The data from food diaries were analyzed using Nutri Flow (Flow-Team, Oulu, Finland) software.

Body composition was estimated using bioimpedance (Inbody 720, Biospace, Soul, South Korea). The assessments were performed after an overnight fast, with the soldiers voiding before the measurement, and wearing only underwear. Blood samples were collected from the ulnar vein using Terumo Venosafe tubes (Terumo Europe, Leuven, Belgium), and were centrifuged at a speed of $3500 \mathrm{rpm}$. Glucose, serum high density lipoprotein cholesterol (HDL) and TG were analyzed with the Konelab 20 XTi device (Thermo Electron Co, Vantaa, Finland), and the isolated LDL fraction was used for the direct measurement of LDL cholesterol with the cholesterol oxidase phenol 4-aminoantipyrine peroxidase (CHOD-PAP) method. The ranges for TG, HDL cholesterol, and LDL cholesterol assays were $0.1-15,0.09-11,0.04-2.84$, and $0.3-8.9 \mathrm{mmol} / \mathrm{l}$, respectively. Intra- and interassay coefficients of variance were $1.0 \%$ and $3.8 \%$ for TGs, $3.4 \%$ and $3.9 \%$ for serum LDL, and $0.5 \%$ and $7.6 \%$ for serum HDL, respectively. Sensitivity for glucose was $0.1 \mathrm{mmol} / \mathrm{l}$, and intra- and interassay coefficients of variance were $1.0 \%$ and $2.0 \%$, respectively. Serum concentrations of CRP, TNF- $\alpha$, and IL- 6 were measured using commercial high sensitivity ELISA kits according to the manufacturer's instructions (Quantikine HS, R\&D Systems, Minneapolis, USA). Assay specifications were $0.10 \mathrm{mg} / \mathrm{l}$ for CRP sensitivity, $0.11 \mathrm{pg} / \mathrm{ml}$ for IL-6, and $0.19 \mathrm{pg} / \mathrm{mL}$ for TNF- $\alpha$. The maximum intra- 


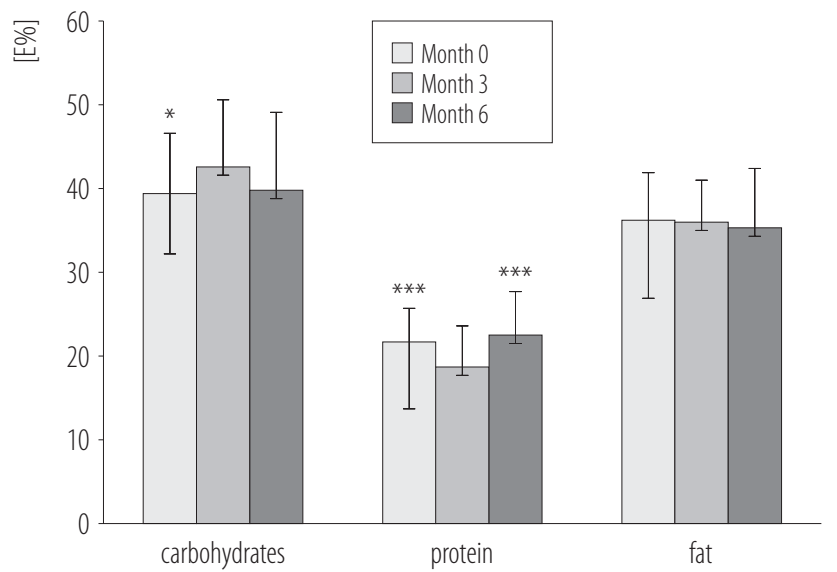

$* \mathrm{p}<0.05 ; * * \mathrm{p}<0.001$

Figure 1. Macronutrient intake [E\%] of soldiers $(\mathrm{N}=35)$ during a 6-month deployment in Southern Lebanon, in the study conducted in June-November 2014

and interassay coefficients of variance were $4.8 \%$ and $6.1 \%$ for CRP, $5.9 \%$ and $9.8 \%$ for IL-6, and $6.1 \%$ and $7.7 \%$ for TNF- $\alpha$, respectively.

Blood pressure was measured after a 5-min rest, 3 times at 2-min intervals, by a semiautomatic blood pressure device (Omron M6 Comfort, Omron Healthcare, Kyoto, Japan). The means of the 3 measurements were used for statistical analyses.

Data are presented as $\mathrm{M} \pm \mathrm{SD}$. A paired t-test was used to examine differences in the means between measurement points, and Bonferroni adjustments were used when needed.

The linear correlation between nutritional or body composition variables and CVD risk factors was obtained using Pearson's product-moment correlation. For TG, PUFAs, and IL-6, Spearman's rank correlation coefficient was utilized. Linear regression analyses were conducted to examine linear relationships between nutritional or body composition parameters and CVD risk factors or inflammatory markers. All the analyses were carried out using commercial software (IBM SPSS 25.0.0, Chicago, Illinois, USA), and p-values of $<0.05$ were considered statistically significant.

\section{RESULTS}

The variation in macronutrient distribution is shown in Figure 1. Carbohydrate intake (E\%) increased between months 0 and 3 (39.4 E\%, $42.6 \mathrm{E} \%$; $\mathrm{p}=0.034$ ), while protein intake $(\mathrm{E} \%)$ first decreased $(21.7 \mathrm{E} \%, 18.7 \mathrm{E} \%$; $\mathrm{p}<0.001)$ but then recovered $(22.5 \mathrm{E} \%$; $\mathrm{p}<0.001)$. Fiber intake decreased between months 3 and 6 ( $21.4 \mathrm{~g}$ /day vs. $16.5 \mathrm{~g} / \mathrm{day}, \mathrm{p}=0.002$ ). The intake of SFAs was $12-13 \mathrm{E} \%$ and PUFAs 8-12 E\% during the operation. The mean energy intake was $10.5 \pm 2.8 \mathrm{MJ} /$ day. Body composition remained stable during the study period (Table 1).

The relative prevalence of soldiers having dyslipidemia, hyperglycemia, hypertension, or a high level of inflammatory markers in the present study is shown in Table 2. The highest prevalence of dyslipidemia was found in LDL cholesterol: $31.4 \%, 40.0 \%, 34.3 \%$ of soldiers exceeded the reference value (at months 0,3 and 6 , respectively). A total of $68.6 \%$ of soldiers had high systolic blood pressure (>120 mm Hg) at month 6, while the earlier results were $31.3 \%$ (at month 0 ) and $40.0 \%$ (at month 3).

The mean concentrations of total, HDL and LDL cholesterol, TG and glucose are presented in Table 3. Lipid and glucose concentrations did not change between the measurements and the mean values were within the reference values during the deployment. In addition, TNF- $\alpha$ decreased by $8 \%$ at month 6 , compared to month 0 and 3; CRP was measured but, due to analytical problems, the number of samples remained low $(\mathrm{N}=15)$; and the $\mathrm{M} \pm \mathrm{SD}$ values were $3.87 \pm 7.59$, $1.80 \pm 1.09,1.73 \pm 3.14$ at months 0,3 , and 6. Systolic blood pressure was the highest at month 6 , compared to months 0 and 3 .

No systematic associations between nutrient intake and CVD risk factors or inflammatory markers were found at any measurement point. When considering changes between months 0 and 6, negative associations were found between the changes in fiber intake and the changes in to- 
Table 1. Body composition of soldiers $(\mathrm{N}=35)$ during a 6-month deployment in Southern Lebanon, in the study conducted in June-November 2014

\begin{tabular}{|c|c|c|c|}
\hline \multirow[t]{2}{*}{ Variable } & \multicolumn{3}{|c|}{$\begin{array}{l}\text { Body composition } \\
(\mathrm{M} \pm \mathrm{SD})\end{array}$} \\
\hline & month 0 & month 3 & month 6 \\
\hline Body mass $[\mathrm{kg}]$ & $77.1 \pm 8.9$ & $77.1 \pm 9.0$ & $77.5 \pm 9.6$ \\
\hline Skeletal muscle mass $[\mathrm{kg}]$ & $38.0 \pm 4.2$ & $38.1 \pm 4.1$ & $38.4 \pm 4.7$ \\
\hline Fat mass $[\mathrm{kg}]$ & $10.8 \pm 4.1$ & $10.6 \pm 4.1$ & $10.6 \pm 3.8$ \\
\hline Body fat $[\%]$ & $13.8 \pm 4.4$ & $13.5 \pm 4.3$ & $13.5 \pm 4.0$ \\
\hline Visceral fat area $\left[\mathrm{cm}^{2}\right]$ & $49.7 \pm 17.5$ & $51.7 \pm 22.8$ & $50.3 \pm 20.5$ \\
\hline
\end{tabular}

No statistically significant changes in any variable.

Table 2. Dyslipidemia, hyperglycemia, high level of pro-inflammatory biomarkers and hypertension of soldiers $(\mathrm{N}=35)$ during a 6-month deployment in Southern Lebanon, in the study conducted in June-November 2014

\begin{tabular}{|c|c|c|c|}
\hline \multirow[t]{2}{*}{ Variable } & \multicolumn{3}{|c|}{$\begin{array}{c}\text { Prevalence } \\
{[\%]}\end{array}$} \\
\hline & month 0 & month 3 & month 6 \\
\hline \multicolumn{4}{|l|}{ Cholesterol } \\
\hline high total $[>5.0 \mathrm{mmol} / 1]^{\mathrm{a}}$ & 28.6 & 31.4 & 28.6 \\
\hline low $\mathrm{HDL}[<1.0 \mathrm{mmol} /]^{\mathrm{a}}$ & 22.9 & 22.9 & 8.6 \\
\hline high LDL $[>3.0 \mathrm{mmol} / 1]^{\mathrm{a}}$ & 31.4 & 40.0 & 34.3 \\
\hline Hypertriglyceridemia $[>1.7 \mathrm{mmol} / \mathrm{l}]^{\mathrm{a}}$ & 8.6 & 8.6 & 8.6 \\
\hline Hyperglycemia $[>6.0 \mathrm{mmol} / \mathrm{l}]^{\mathrm{b}}$ & 2.9 & 0 & 2.9 \\
\hline High interleukin-6 $[>3.4 \mathrm{ng} /]^{\mathrm{c}}$ & 5.9 & 8.8 & 2.9 \\
\hline High tumor necrosis factor $\alpha[>8.1 \mathrm{ng} /]^{\mathrm{c}}$ & 36.4 & 39.4 & 21.2 \\
\hline \multicolumn{4}{|l|}{$\begin{array}{l}\text { High blood pressure } \\
\text { systolic }\end{array}$} \\
\hline$>120 \mathrm{~mm} \mathrm{Hg}^{\mathrm{d}}$ & 31.4 & 40.0 & 68.6 \\
\hline$>140 \mathrm{~mm} \mathrm{Hg}^{\mathrm{d}}$ & 2.9 & 2.9 & 8.6 \\
\hline \multicolumn{4}{|l|}{ diastolic } \\
\hline$>80 \mathrm{~mm} \mathrm{Hg}^{\mathrm{d}}$ & 20.0 & 22.9 & 28.6 \\
\hline$>90 \mathrm{~mm} \mathrm{Hg}^{\mathrm{d}}$ & 2.9 & 8.6 & 5.7 \\
\hline
\end{tabular}

${ }^{\text {a }}$ Reference values for lipids based on [21].

${ }^{\mathrm{b}}$ Reference value for blood glucose based on [22].

${ }^{\mathrm{c}}$ Reference values for interleukin- 6 based on [23].

${ }^{\mathrm{d}}$ Reference values for tumor necrosis factor- $\alpha$ based on [24].

tal and LDL cholesterol concentrations $(\mathrm{R}=-0.362, \mathrm{p}=\quad$ Scatter plots of the positive correlations between BF\%, $0.033 ; \mathrm{R}=-0.394, \mathrm{p}=0.019$, respectively). No other as- $\quad$ total and LDL cholesterol concentrations at baseline are sociations were observed. shown in Figures 2a and 2b. It was found that BF\% and fat 
Table 3. Cardiovascular risk factors and pro-inflammatory biomarkers in soldiers ( $\mathrm{N}=35$, except tumor necrosis factor $\alpha$ [TNF- $\alpha$ ], $\mathrm{N}=34$; abnormal values), during a 6-month deployment in Southern Lebanon, in the study conducted in June-November 2014

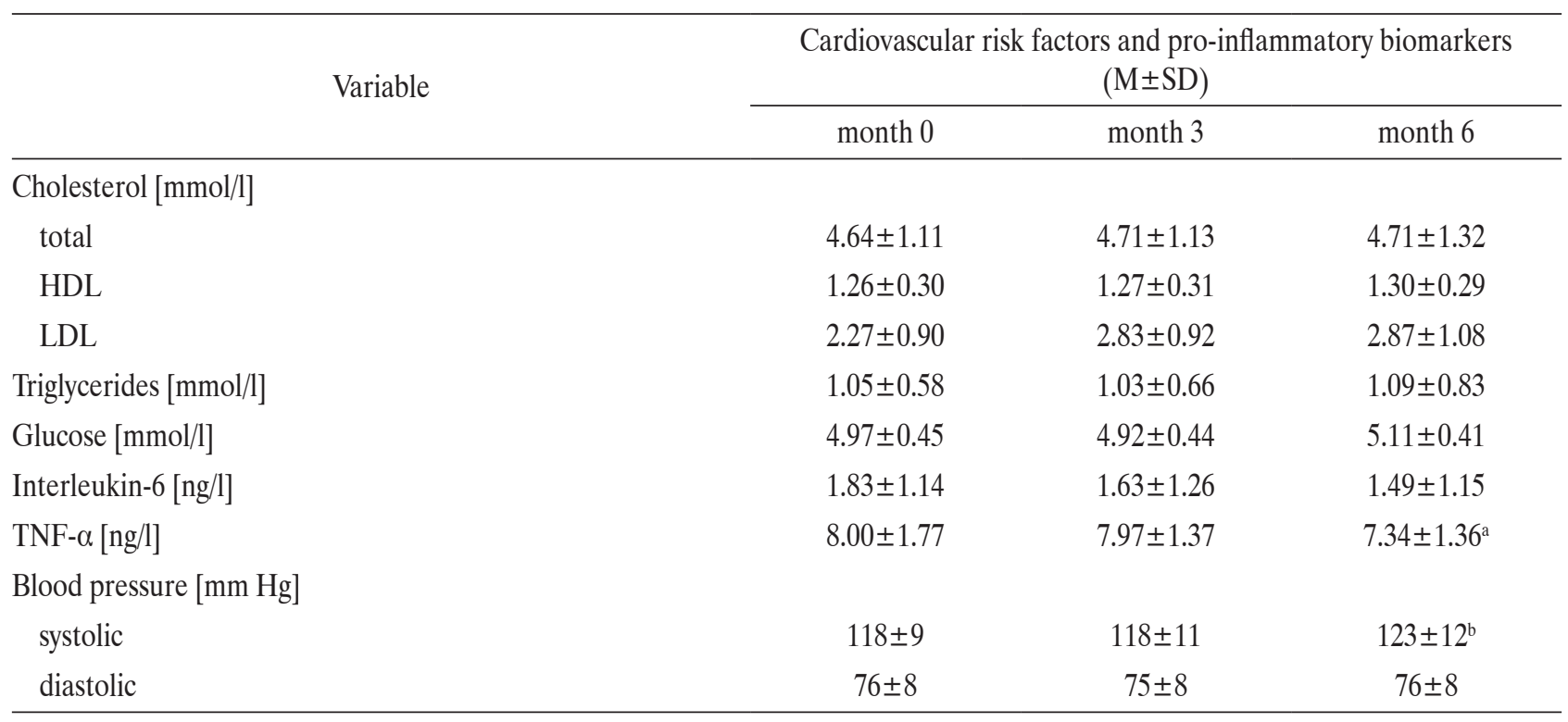

No statistically significant changes in other variables except TNF- $\alpha$ and systolic blood pressure: ${ }^{a}$ months $0-6: p=0.01$, months $3-6: p=0.006$; ${ }^{\mathrm{b}}$ months $0-6: \mathrm{p}=0.008$, months $3-6: \mathrm{p}=0.008$.

mass correlated positively with total and LDL cholesterol concentrations at all measurement points.

\section{DISCUSSION}

Carbohydrate intake increased and protein intake decreased at month 3 , but these did not have an association with CVD risk factors or pro-inflammatory biomarkers at any measurement points. The change in fiber intake was inversely associated with the change in total and LDL cholesterol concentrations. In addition, $\mathrm{BF} \%$, fat mass, skeletal muscle mass, and body weight were stable during the operation, but $\mathrm{BF} \%$ and fat mass associated positively with total and LDL cholesterol concentrations at all measurement points. When considering CVD risk factors, the mean systolic blood pressure increased at month 6 over the optimal level. The highest prevalence of dyslipidemia was found in the LDL cholesterol concentration at month 3 where $40 \%$ of the participants had values exceeding the recommended level.
Fiber intake of the participants remained below the recommended levels (25-35 g/d) [9] throughout the study, and the change in fiber intake was negatively associated with the change in total and LDL cholesterols concentrations. The negative association between dietary fiber and total and LDL cholesterol concentrations has been well established [25]. Likewise, low fiber intake is associated with a higher CVD risk [26]. During military education, low fiber intake was found in $92.7 \%$ of Brazilian cadets and hypercholesterolemia in $50.7 \%$ of them [5]. In submariners, fiber intake remained $<25 \mathrm{~g} / \mathrm{d}$ in obese and non-obese participants during their 3-month patrolling, but modest improvements in serum lipids were observed, mostly related to reduced body weight and body fat mass [7]. Overall, the increased intake of fiber-rich foods, like whole grain products, fruit and vegetables, could improve cardiometabolic health, insulin sensitivity, and weight management, as well as prevent gastrointestinal disorders [26]. 
According to the Nordic Nutrition Recommendations, fat intake should range 25-40 E\% [9]. The quality of dietary fat seems to be more important than its quantity for lowering the CVD risk [8]. Replacing SFAs by unsaturated fatty acids, especially PUFAs, lowers the CVD risk [27]. In this study, fat intake ranged 35-36 E\% and the intake of SFA 12-13 E\%. The consumption of butter, high-fat dairy and meat products can explain the high amount of SFAs during the operation. Replacing butter with soft spreads and using vegetable oils in cooking and salad dressing might lower the intake of SFAs and increase the intake of PUFAs in all military personnel living in a camp.

Fat mass and $\mathrm{BF} \%$ were associated positively with total and LDL cholesterol concentrations, which has also been well documented in previous studies [15,16,28]. Although obesity is a clear risk factor for diabetes and CVDs [15, 28], fat distribution, and especially visceral fat, may be more accurate for the evaluation of the CVD risk than fat mass or $\mathrm{BF} \%$ [16]. The amount of abdominal fat, which can be measured by waist circumference or the visceral fat area, may predict abnormalities in cardiometabolic health $[15,16]$. In this study, waist circumference and the visceral fat area were measured, but these data were excluded due to some inaccuracies of the measurements. Altogether, body fat and $\mathrm{BF} \%$ are associated with hyperlipidemia, also in soldiers. The follow-up of body composition during a military operation could be useful for evaluating the CVD risk and for adjusting physical training.

Systolic blood pressure increased between months 0 and 3 , and month 6 , and the mean value exceeded the recommended level, but associations with dietary intake or body composition were not found. Previously, it has been demonstrated that a diet low in total and saturated fats, and high in fruit and vegetables and low-fat dairy products, reduces blood pressure and LDL cholesterol [12]. A partial replacement of refined carbohydrates with protein or unsaturated fat can further decrease blood pressure [11,12]. It is well known that psycho-social factors like occupa-
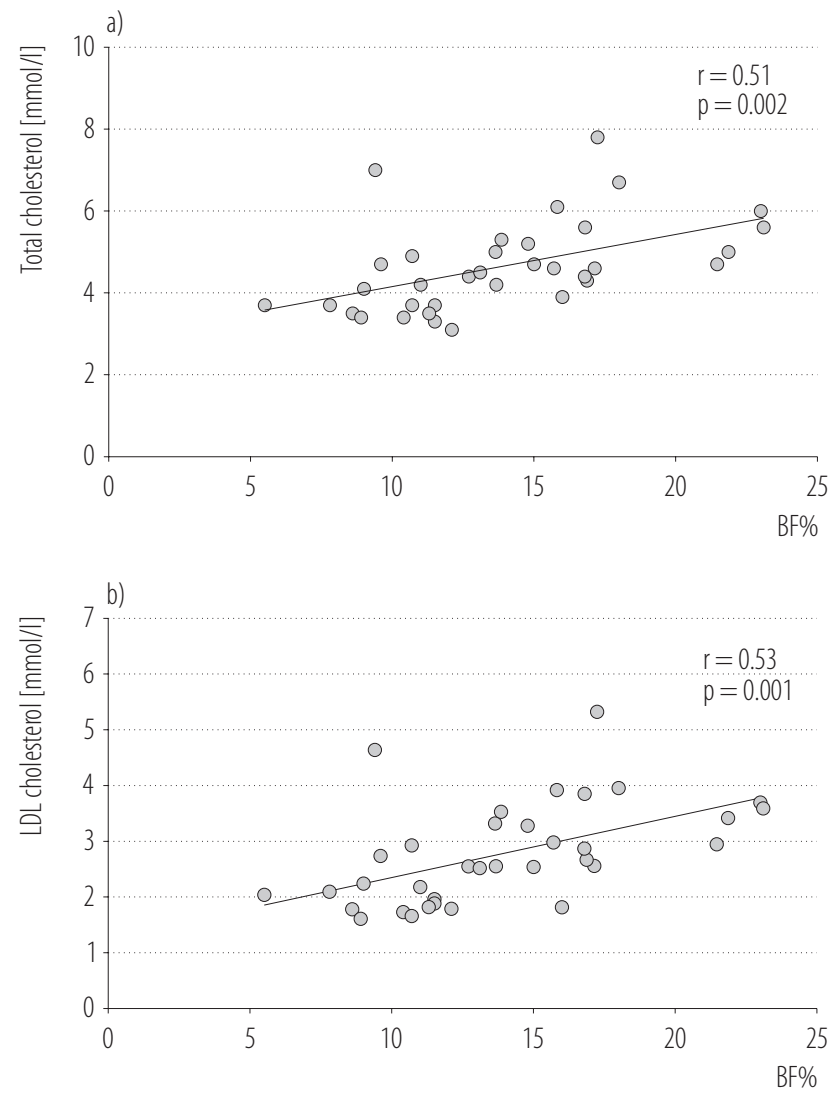

Figure 2. Relationship between body fat percentage (BF\%) and a) total cholesterol, b) LDL cholesterol concentration at baseline of soldiers $(\mathrm{N}=35)$ during a 6 -month deployment in Southern Lebanon, in the study conducted in June-November 2014

tional stress, personality, mental health, and sleep quality, may contribute to the development of hypertension [29]. In a separate questionnaire (data not shown), the participants reported monotonous life and depressive symptoms, especially during the second half of the deployment, which may partly explain their elevated systolic blood pressure. Therefore, a regular monitoring of blood pressure might be reasonable for those soldiers whose blood pressure was elevated at the end of the study.

Low-grade systemic inflammation can predict cardiovascular events $[19,30]$. Higher concentrations of TNF- $\alpha$ and IL-6 can promote this kind of inflammation, which might increase the CVD risk. In this study, TNF- $\alpha$ was decreased 
at month 6 and IL- 6 remained stable. While CRP exceeded the normal range at baseline, these values cannot be generalized due to a small sample size. When considering all 3 inflammatory markers together, a moderately decreasing trend over the time-course of the operation was observed. Dietary intake and body composition did not correlate with pro-inflammatory biomarkers in these data, but a recent study has shown that dietary fats and carbohydrates could relate to inflammatory processes, yet the pathways are still unclear [30]. The individual variability in inflammatory responses, as well as the validity of biomarkers, must be considered when interpreting the values [30]. High concentrations of inflammatory markers have been measured in soldiers after stressful combat training, highpressure operational situations, and in post-traumatic stress reactions [20,31]. The tension in military operations has been found to increase shortly during mid-phase measurements, but this cannot be seen in inflammatory markers. To conclude, clear explanations for the decreasing trend of inflammatory biomarkers were not found in this study. Thus, more studies are needed to clarify the inflammatory responses in military environments, as well as acute and chronic effects of such responses on the health of soldiers.

Regular exercise has multiple positive effects on CVD risk factors [32]. The physical activity of this operation has been reported elsewhere [33]. The results indicated that total physical activity, estimated by accelerometers, was very low throughout the study and stress hormone responses did not show any overload symptoms. Associations between physical activity and CVD risk factors have not been observed yet.

The data were collected on site during the deployment, which makes this study unique compared to other military operation studies [14,18]. Controlled methods were used for all variables, and the sample was representative in terms of age, sex, body composition and physical fitness. A limitation is that the sample size remained small and the statistical power was rather low. A bioimpedance analysis is not as valid as dual-energy X-ray absorptiometry, but it is a simple and portable method for estimating body composition in standardized circumstances [34]. In food diaries, underreporting, forgetting, and motivational problems may have an effect on the accuracy of reporting [35]. However, most of the consumed food items were familiar to the participants and found in the database embedded in the software. The rapid changes in operational situations were reflected in diet, physical training and sleep, especially at month 3 .

\section{CONCLUSIONS}

Low fiber intake and a greater amount of body fat were associated with high total and LDL cholesterol concentrations, while a higher systolic blood pressure was measured at the end of the study. These results show that soldiers are exposed to the same CVD risk factors as civilians although they are not regarded as a risk group for cardiometabolic disorders. A systemic follow-up of body composition and adherence to a fiber-rich diet during operations might be useful to optimize cardiometabolic health in soldiers. Inflammatory responses to military work and its contribution to the CVD risk are an interesting area for future research.

\section{ACKNOWLEDGMENTS}

The authors would like to thank Ms. Mia Laakso for her assistance in data analysis, Mr. Pasi Ollila, Mr. Risto Puurtinen and Mrs. Aila Ollikainen for their blood analyses, Mr. Jani Raitanen for statistical analyses, and Mrs. Ritva Taipale for linquistic review.

\section{REFERENCES}

1. World Health Organization [Internet]. Prevention of cardiovascular disease. Guidelines for assessment and management of cardiovascular risk. Geneva: The Organization; 2004 [cited 2019 Sep 12]. Available from: https://www.who.int/cardiovascular_diseases/guidelines/Full\%20text.pdf. 
2. Hruby A, Bulathsinhala L, McKinnon CJ, Hill OT, Mountain SJ, Young AJ, et al. Body mass index at accession and incident cardiometabolic risk factors in US army soldiers, 2001-2011. PLoS One. 2017;12(1):e0170144, https://doi.org/ 10.1371/journal.pone.0170144.

3. Funderburk LK, Arsenault JE. Prevalence of abnormal serum lipids among overweight and obese soldiers. Mil Med 2013;178(10):1137-40, https://doi.org/10.7205/MILMED-D13-00096.

4. Mullie P, Clarys P, Hulens M, Vansant G. Distribution of cardiovascular risk factors in Belgian army men. Arch Environ Occup Health. 2010;65(3):135-9, https://doi.org/10.1080/193 38240903390339.

5. Hilgenberg FE, Santos AS, Silveira EA, Cominetti C. Cardiovascular risk factors and food consumption of cadets from the Brazilian Air Force Academy. Cien Saude Colet. 2016;21(4):116574, https://doi.org/10.1590/1413-81232015214.15432015.

6. Pasiakos SM, Karl JP, Lutz LJ, Murphy NE, Margolis LM, Rood JC, et al. Cardiometabolic risk in US army recruits and the effects of basic combat training. PLoS One. 2012;7(2): e31222, https://doi.org/10.1371/journal.pone.0031222.

7. Gasier HG, Young CR, Gaffney-Stomberg E, McAdams DC, Lutz LJ, McClung JP. Cardiometabolic health in submariners returning from a 3-month patrol. Nutrients. 2016;8(2):85, https://doi.org/10.3390/nu8020085.

8. Schwab U, Lauritzen L, Tholstrup T, Haldorsson TI, Riserus $\mathrm{U}$, Uusitupa $\mathrm{M}$, et al. Effect of the amount and type of dietary fat on cardiometabolic risk factors and risk of developing type 2 diabetes, cardiovascular diseases, and cancer: a systematic review. Food Nutr Res. 2014;10(58), https://doi. org/10.3402/fnr.v58.25145.

9. Nordic Council of Ministers [Internet]. Nordic Nutrition Recommendations 2012. Integrating nutrition and physical activity. Copenhagen: Nordic Co-operation; 2014 [cited 2019 Sep 12]. Available from: https://doi.org/10.6027/Nord2014-002.

10. Siri-Tarino PW, Sun Q, Hu FB, Krauss RM. Saturated fat, carbohydrate, and cardiovascular disease. Am J Clin Nutr. 2000;91(3):502-9, https://doi.org/10.3945/ajcn.2008.26285.
11. Appel LJ. The effects of protein intake on blood pressure and cardiovascular disease. Curr Opin Lipidol. 2003;14(1):55-9.

12. Appel LJ, Sacks FM, Carey VJ, Obarzanek E, Swain JF, Miller ER, et al. Effects of protein, monounsaturated fat, and carbohydrate intake on blood pressure and serum lipids: results of the OmniHeart randomized trial. JAMA. 2005;294(19): 2455-64, https://doi.org/10.1001/jama.294.19.2455.

13. Beals K, Damell ME, Lovalekar M, Baker RA, Nagai T, SanAdams T, et al. Suboptimal nutritional characteristics in male and female soldiers compared to sports nutrition guidelines. Mil Med. 2015;180(12):1239-46, https://doi.org/10.7205/ MILMED-D-14-00515.

14. Fallowfield J, Delves S, Hill N, Cobley R, Brown P, Lanham-New S, et al. Energy expenditure, nutritional status, body composition and physical fitness of Royal Marines during a 6-month operational deployment in Afghanistan. Br J Nutr. 2014;112(5):821-9, https://doi.org/10.1017/ S0007114514001524.

15. Huxley R, Mendis S, Zheleznyakov E, Reddy S, Chan J. Body mass index, waist circumference and waist:hip ratio as predictors of cardiovascular risk - a review of the literature. Eur J Clin Nutr. 2010;64(1):16-22, https://doi.org/10.1038/ejcn. 2009.68 .

16. Despres JP. Body fat distribution and risk of cardiovascular disease. Circulation. 2012;126(10):1301-13, https://doi. org/10.1161/CIRCULATIONAHA.111.067264.

17. Tassone EC, Baker BA. Body weight and body composition during military training and deployment involving the use of combat rations: a systematic review. Eur J Clin Nutr. 2017;117(6):897-910, https://doi.org/10.1017/S00071145170 00630 .

18. Sharp M, Knapik J, Walker L, Burrell L, Frykman P, Darakjy S, et al. Physical fitness and body composition after a 9-month deployment to Afghanistan. Med Sci Sports Exerc. 2008;40(9): 1687-92, https://doi.org/10.1249/MSS.0b013e318176b978.

19. Libby P. Inflammation and cardiovascular disease mechanisms. Am J Clin Nutr. 2006;83(2):456S-60S, https://doi.org/ 10.1093/ajcn/83.2.456S. 
20. Groer MW, Kane B, Williams SN, Duffy A. Relationship of PTSD symptoms with combat exposure, stress, and inflammation in American soldiers. Biol Res Nurs. 2015;17(3):30310, https://doi.org/10.1177/1099800414544949.

21. Tarnanen K, Strandberg T, Syvänne M, Schwab U, Kukkonen-Harjula K. Dyslipidemias: Current Care Guidelines [Internet]. Helsinki: The Finnish Medical Society Duodecim; 2018 [cited 2019 Jun 24]. Available from: https://www. kaypahoito.fi/khp00047.

22. Tarnanen K, Tuomi T, Meinander T. Type 2 Diabetes: Current Care Guidelines [Internet]. Helsinki: The Finnish Medical Society Duodecim; 2018 [cited 2019 Jun 24]. Available from: https://www.kaypahoito.fi/khp00066.

23. HUSLAB - tutkimusohjekirja. [Interleukiini 6, plasmasta] [Internet]. Helsinki: HUSLAB Laboratorio. [cited 2019 Jun 24]. Available from: https://huslab.fi/cgi-bin/ohjekirja/ tt_show.exe?assay $=4842 \&$ terms $=$ interleukiini, 6 . Finnish

24. HUSLAB - tutkimusohjekirja. [Tuumorinekroositekijä, alfa, seerumista] [Internet]. Helsinki: HUSLAB Laboratorio [cited 2019 Jun 24]. Available from: https://huslab.fi/cgi-bin/ ohjekirja/tt_show.exe?assay $=4282 \&$ terms $=$ tuumorinekroo si. Finnish.

25. Tarnanen K, Jula A, Komulainen J. Hypertension: Current Care Guidelines [Internet]. Helsinki: The Finnish Medical Society Duodecim; 2015 [cited 2019 Jun 24]. Available from: https://www.kaypahoito.fi/khp00016.

26. Stephen AM, Champ MM, Cloran SJ, Fleith M, van Lieshout L, Mejborn H, et al. Dietary fibre in Europe: current state of knowledge on definitions, sources, recommendations, intakes and relatioships to health. Nutr Res Rev. 2017;30(2):149-90, https://doi.org/10.1017/S095442241 $700004 \mathrm{X}$.

27. Wang DD, Hu FB. Dietary fat and risk of cardiovascular disease: recent controversies and advances. Annu Rev Nutr. 2017;37(1):423-46, https://doi.org/10.1146/annurev-nutr-071 816-064614.
28. Freedman DS, Ogden CL, Kit BK. Interrelationships between BMI, skinfold thicknesses, percent body fat, and cardiovascular disease risk factors among U.S. children and adolescents. BMC Pediatr. 2015;15:188, https://doi.org/ 10.1186/s12887-015-0493-6.

29. Cuffee Y, Ogedegbe C, Williams NJ, Ogedegbe G, Schoenthaler A. Psychosocial risk factors for hypertension: an update of the literature. Curr Hypertens Rep. 2014;16(10):483, https://doi.org/10.1007/s11906-014-0483-3.

30. Minihane AM, Vinoy S, Russell WR, Baka A, Roche HM, Tuohy KM, et al. Low-grade inflammation, diet composition and health: current research evidence and its translation. Br J Nutr. 2015;114(7):999-1012, https://doi.org/10.1017/ S0007114515002093.

31. Li X, Kan EM, Lu J, Cao Y, Wong RK, Keshavarzian A, et al. Combat-training increases intestinal permeability, immune activation and gastrointestinal symptoms in soldiers. Aliment Pharmacol Ther. 2013;37(8):799-809, https://doi. org/10.1111/apt.12269.

32. Tian D, Meng J. Exercise for prevention and relief of cardiovascular disease: prognoses, mechanisms, and approaches. Oxid Med Cell Long. 2019;3756750, https://doi. org $/ 10.1155 / 2019 / 3756750$.

33. Pihlainen K, Santtila M, Vasankari T, Häkkinen K, Kyröläinen $\mathrm{H}$. Evaluation of occupational physical load during 6-month international crisis management operation. Int $\mathrm{J}$ Occup Med Environ Health. 2018;31(2):185-97, https://doi. org/10.13075/ijomeh.1896.01048.

34. Langer RD, Borges JH, Pascoa MA, Cirolini VX, GuerraJúnior G, Gonçalves EM. Validity of bioelectrical impedance analysis to estimation fat-free mass in the army cadets. Nutrients. 2016;8(3):121, https://doi.org/10.3390/nu8030121.

35. Capling L, Beck KL, Gifford JA, Slater G, Flood VM, O'Connor H. Validity of dietary assessment in athletes: A systematic review. Nutrients. 2017;9(12):1313, https://doi.org/10. 3390/nu9121313.

This work is available in Open Access model and licensed under a Creative Commons Attribution-NonCommercial 3.0 Poland License - http://creativecommons.org/ licenses/by-nc/3.0/pl/deed.en. 